\title{
SECAGEM ESTACIONÁRIA DE SEMENTES DE TRIGO COM UTILIZAÇÃO DE GÁS LIQUEFEITO DE PETRÓLEO ${ }^{1}$
}

\author{
MELISSABERTI², DIRK CLÁUDIOAHRENS ${ }^{3}$, DANIELEREGINABEUSSO ${ }^{4}$
}

\begin{abstract}
RESUMO - O objetivo deste trabalho foi verificar a qualidade física e fisiológica das sementes de trigo em função da utilização de gás liquefeito de petróleo (GLP) na secagem estacionária e determinar a curva de secagem em comparação à secagem estacionária em estufa. Sementes de trigo, cultivar OR-I, com teor de água inicial de 15,3\%, foram secas até 12,6\%, em um secador estacionário de tubo central horizontal perfurado. A amostragem das sementes foi realizada em intervalos de 45 minutos durante a secagem, em três posições diferentes do cilindro central (proximal, mediana e distal da fonte de calor). A qualidade física da semente foi avaliada pelo teor de água, peso de mil sementes e temperatura da massa de semente em pontos distintos. A qualidade fisiológica foi avaliada por testes de vigor e germinação. A velocidade média obtida na secagem a gás foi de 0,9 pontos percentuais por hora $\left(\mathrm{pph}^{-1}\right)$. O tempo dispendido para a redução do teor de água de 15,3\% para 12,6\%, foi de três horas, além de mais uma hora usada para o resfriamento da semente. A velocidade de secagem reduz a medida que aumenta a distância das sementes ao cilindro central (no ponto proximal à fonte de calor 1,00 $\mathrm{pph}^{-1} \mathrm{e}$ no ponto distal $0,73 \mathrm{pph}^{-1}$ ), em função da temperatura da massa de sementes ser maior no ponto proximal. A temperatura na massa de semente aumenta gradativamente nos pontos mais próximos à fonte de calor durante a secagem. A temperatura de secagem permanece estável durante o processo com a utilização de gás liquefeito de petróleo. Os resultados dos testes de germinação e vigor mostram a possibilidade de utilização do gás liquefeito de petróleo como combustível na secagem estacionária de sementes de trigo.
\end{abstract}

Termos para indexação: teor de água, temperatura, germinação, emergência das plântulas.

\section{STATIONARY DRYING OF WHEAT SEEDS USING PETROLEUM LIQUIFIED GAS}

\begin{abstract}
The purpose of this study was to verify wheat seed physiological and physical quality while using petroleum liquified gas (LPG) for stationary drying and to determine the drying curve in comparison to the stationary drying in an oven. Wheat seeds, variety OR-I, with 15,3\% initial water contents were dried down to $12,6 \%$, in a stationary dryer with a perforated horizontal central tube. Samples were taken at $45 \mathrm{~min}$. intervals of the seeds set in three different positions from the central cylinder (proximal, median and distal from the heat source), during the drying process. The physical seed quality was evaluated by water contents, weight of one thousand seeds, temperature of the seeds mass at different points. The physiological seed quality was evaluated by germination and vigor. The average speed obtained in the drying by gas was 0,9 percent points per hour $\left(\mathrm{pph}^{-1}\right)$. The seeds were dried down from 15,3\% to 12,6\%, taking three hours, plus one more hour for cooling. The drying speed was reduced as the distance of the seeds from the central cylinder increased (at the proximal point to the heat source $1,00 \mathrm{pph}^{-1}$ and at the distal point $0,73 \mathrm{pph}^{-1}$ ) because the temperature of the seed mass was higher at the proximal point. The temperature of the seed mass increased gradually in the points closer to the heat source
\end{abstract}

${ }^{1}$ Submetido em 17/03/2004. Aceito para publicação em 06/05/2005.

${ }^{2}$ Eng $^{\mathrm{a}}$ Agr ${ }^{\mathrm{a}}$ Melissa Berti, Rua Araruva 405 CEP 84015-530, Ponta Grossa, PR. melissaberti@yahoo.com.br
${ }^{3}$ Eng $^{\circ}$ Agr $^{\circ}$ Dr. Pesquisador do IAPAR, C.P.129, CEP 84001-970, Ponta Grossa,PR.dahren@pr.gov.br

${ }^{4}$ Acadêmica do curso de Agronomia da Universidade Estadual de Ponta Grossa. 
during the drying process. The seed physiological quality was assessed by tests of germination and vigor, which demonstrated the possibility of using petroleum liquefied gas in the drying process with the temperatures applied.

Index terms: water contents, temperature, germination, seedling emergence.

\section{INTRODUÇÃO}

A secagem tem contribuído para assegurar ao sistema de produção a oferta de sementes com alta qualidade (Silva Filho, 1997). Entretanto, a sensibilidade ao dano térmico entre espécies foi observada por Rosa (1966) utilizando secagem intermitente à temperatura de $80^{\circ} \mathrm{C}$ em sementes de trigo e arroz e por Navratil e Burris (1984), na secagem estacionária de sementes de milho. A temperatura da massa de sementes, também apresenta variações consideráveis entre os equipamentos de secagem, como foi observado na secagem de sementes de milho (Villela e Silva, 1992). Estes fatos são indicativos de que, se por um lado, o aumento da temperatura de secagem pode aumentar a eficiência do processo, por outro, o aumento da eficácia depende também do conhecimento da tolerância da semente ao dano térmico durante a secagem.

A secagem é um processo simultâneo de transferência de calor do ar para a semente e de massa (água) das sementes para o ar (Brooker et al., 1974). Seus métodos são denominados quanto à utilização e equipamentos, podendo ser secagem natural das sementes que depende das condições climáticas. Requerem instalações simples, e tem a desvantagem do uso intensivo de mão-de-obra o que gera um baixo rendimento nas operações. Tem grande importância para produção de sementes, pois a secagem feita ao sol ou à sombra resulta numa padronização da maturação pós-colheita.

Outro método é a secagem artificial, cujo processo é caracterizado pela execução com o auxílio de aparelhos mecânicos, elétricos ou eletrônicos, e o ar é forçado através da massa de sementes. É o tipo de secagem mais freqüente e adapta-se bem aos esquemas de produção de sementes, sendo a secagem rápida e capaz de remover elevadas quantidades de água (Carvalho,1994). Permite manter a qualidade das sementes, quando empregado com critérios técnicos, como a não exposição prolongada a elevadas temperaturas e a elevação da temperatura das sementes até determinados limites (Ahrens et al., 2000a).

A secagem artificial pode ser dividida em três métodos.
Na secagem contínua as sementes entram no secador com determinado teor de água e devem sair, na outra extremidade, com o teor de água que se deseja e com a temperatura mais próxima possível do ambiente. O secador contínuo possibilita o estabelecimento de um fluxo ininterrupto de semente entre a recepção e o armazenamento, sendo eficiente principalmente quando a quantidade de grãos recebida é muito grande. Na secagem intermitente, as sementes passam mais de uma vez tanto na câmara de secagem como pela câmara de equalização. Há um período de repouso, quando ocorre a reidratação da camada externa da semente com água proveniente do seu interior, de forma menos estressada do que na secagem contínua ou estacionária, em geral as sementes ficam continuamente expostas ao ar quente (Carvalho, 1994). Os secadores intermitentes fazem uso pouco eficiente do calor gerado no combustor, pois que, além das perdas de energia térmica que ocorrem em outras partes, neste secador ocorre uma perda muito grande por radiação, a partir das chapas metálicas que recobrem a câmara de secagem durante o tempo em que as sementes estão esfriando na câmara de equalização. Na secagem estacionária ocorre a passagem forçada do ar através da massa de semente que permanece em repouso. Nos secadores de tubo central perfurado o ar passa do centro para a periferia, ocorrendo em camadas em função da formação da frente de secagem, correspondentes às regiões de intercâmbio de água entre as sementes (Ahrens e Lollato, 1997).

Fatores como umidade relativa, temperatura e fluxo do ar, teor de água e espessura da massa e capacidade de transferência de água das sementes para o ar, condicionam o teor de água entre sementes situadas em posições diferentes.

Em secagem estacionária sem ventilação forçada de ar, as sementes de aveia branca atingem temperaturas elevadas (correlacionando com o teor de água na semente), sem que ocorra necessariamente, redução imediata da qualidade fisiológica da semente ou durante o armazenamento (Ahrens et al., 2000b).

Tradicionalmente a fonte de calor empregada é 
proveniente da queima de lenha, que tem por inconveniente o desmatamento, proporcionando danos ao meio ambiente, deixando resíduos que podem depreciar o produto. Também, no processo de secagem tradicional ocorrem oscilações na temperatura do ar de secagem em função de um maior volume de lenha colocada na fornalha.

Na secagem de sementes, o uso de gás liquefeito de petróleo proporciona uma temperatura de controle absoluto, sem oscilações; combustão completa, sem fumaça e fuligem; maior facilidade operacional; possibilita a automação; maior limpeza das instalações; e muitas outras vantagens (Ultragás, 2000).

Em função das informações expostas, o objetivo deste trabalho foi verificar a qualidade física e fisiológica das sementes de trigo em função da utilização de gás liquefeito de petróleo na secagem estacionária e determinar a curva de secagem em comparação à secagem estacionária em estufa.

\section{MATERIALE MÉTODOS}

O trabalho foi conduzido na Cooperativa Agropecuária Castrolanda, em parceria com Instituto Agronômico do Paraná - IAPAR e Universidade Estadual de Ponta Grossa - UEPG, no período de novembro de 2000 a março de 2002. Foram utilizadas sementes de trigo OR-I, com o teor de água inicial de $15,3 \%$ e secas até $12,6 \%$, em secador estacionário de tubo central horizontal perfurado, marca Promog, empregando gás liqüefeito de petróleo (GLP) como combustível. A temperatura máxima do ar de secagem foi de $62^{\circ} \mathrm{C}$ e na massa de sementes atingiu $50^{\circ} \mathrm{C}$.

O experimento foi composto por cinco tratamentos: T0 - testemunha (secagem em estufa sem ventilação forçada, à temperatura constante de $38^{\circ} \mathrm{C}$ ); $\mathrm{T} 1$ - secagem estacionária com temperatura do ar constante de $50 / 62^{\circ} \mathrm{C}\left(50^{\circ} \mathrm{C}\right.$ na saída do secador e $62^{\circ} \mathrm{C}$ na fonte de calor) por 45 minutos, seguida de secagem em estufa a $38^{\circ} \mathrm{C}$; $\mathrm{T} 2$ - secagem estacionária por 90 minutos, a temperatura do ar constante de $50 / 62^{\circ} \mathrm{C}$, seguida de secagem em estufa a temperatura de $38^{\circ} \mathrm{C}$; $\mathrm{T} 3$ - secagem estacionária por 135 minutos, à temperatura constante do ar de $50 / 50^{\circ} \mathrm{C}$, seguida de secagem em estufa a $38^{\circ} \mathrm{C}$; $\mathrm{T} 4$ secagem estacionária por 180 minutos, à temperatura constante de $31 / 31^{\circ} \mathrm{C}$ e aeração para o resfriamento das sementes.

As sementes foram coletadas (em amostras de $4 \mathrm{~kg}$ e três repetições) em três pontos distintos em relação à fonte de calor, onde: $1^{\circ}$ ponto (P1): extremidade proximal da fonte;

$2^{\mathrm{o}}$ ponto (P2): centro do secador;

$3^{\circ}$ ponto (P3): extremidade distal da fonte.

Após estarem secas a 12,6\%, as amostras foram divididas em duas partes A e B. Com a parte A foram feitas determinações da qualidade física e fisiológica das sementes imediatamente após a secagem. A parte B foi empregada para avaliação após 180 dias, permanecendo as sementes armazenadas sob condições não controladas, com a finalidade de verificar possíveis danos latentes por secagem.

Para as avaliações da qualidade física foram utilizados os seguintes testes: a) Teor de água: foi utilizado o determinador de umidade Dicy - John, modelo Multi - Grain; b) Temperatura da massa de sementes: obtida com o emprego de termômetro de bulbo acoplado, perpendicularmente, ao recipiente de isopor por quatro minutos, sendo estas medidas realizadas em intervalos regulares de 45 minutos, nos três pontos distintos em relação à fonte de calor, durante 180 minutos; c) Peso de mil sementes: cada amostra foi dividida em oito subamostras de 100 sementes provenientes da porção semente pura, sendo pesadas em balança de precisão 0,001, conforme as Regras para Análise de Sementes (Brasil, 1992).

Para avaliações da qualidade fisiológica foram utilizados os seguintes testes, em dezembro e maio: a) Germinação: realizado com duas repetições de 100 sementes por amostra, seguindo-se metodologia das Regras para Análise de Sementes (Brasil, 1992). As amostras foram submetidas a três dias no frio $\left(5\right.$ a $\left.10^{\circ} \mathrm{C}\right)$, para promover superação de dormência, em seguida foram colocadas em germinador regulado à temperatura de $20^{\circ} \mathrm{C}$, durante cinco dias. Ao final desse período, foi feita a avaliação para obtenção da germinação; b) Teste de envelhecimento acelerado: as sementes (quatro repetições de 50 sementes) foram dispostas em tela metálica, acoplada a caixa plástica (gerbox) com $40 \mathrm{~mL}$ de água, permanecendo em câmara B.O.D. por 60 horas, a $41^{\circ} \mathrm{C}$. Após, instalou-se o teste de germinação (Brasil, 1992). Ao finalizar o período de cinco dias em germinador regulado a $20^{\circ} \mathrm{C}$, procedeu-se a contagem das sementes germinadas; c) Emergência em campo: realizado em duas épocas, a primeira logo após a secagem e a segunda, após 180 dias. Para cada amostra, foram utilizadas duas repetições de 50 sementes, semeadas em canteiro com $1 \mathrm{~m}$ de largura, espaçadas a $5 \mathrm{~cm}$. Realizaram-se duas contagens, a primeira aos 14 dias após a semeadura e a segunda, sete após a primeira contagem.

O delineamento experimental foi inteiramente casualizado, esquema fatorial $5 \times 3$, com três repetições, fazendo-se análise de regressão polinomial e comparação de média pelo teste de Tukey. 


\section{RESULTADOS E DISCUSSÃO}

Observando os resultados da Tabela 1, verificou-se que, com o aumento da temperatura do ar nos diferentes pontos de amostragem, a temperatura da massa de sementes comportou-se distintamente. Assim, a temperatura da massa de sementes nos pontos de verificação, até 90 minutos de secagem, cresceu inversamente proporcional ao teor de água (Figura 1). A partir daí, houve redução na temperatura da massa no P1 (mais próximo ao cilindro), em função da redução da fonte de calor durante a passagem de $\mathrm{T} 2$ para $\mathrm{T} 3,49,7^{\circ} \mathrm{C}$ para $46,3^{\circ} \mathrm{C}$ devido à redução gradual ao final da secagem. Na cultura do arroz, as sementes mais próximas ao cilindro central não apresentaram diferenças entre as temperaturas das sementes (Corrêa, 1981), enquanto que em soja, constatou-se gradientes de até $15^{\circ} \mathrm{C}$ (Pasin, 1991). Em sementes de milho, Cavariani et al. (1999) observaram gradiente de temperatura na massa de sementes maior, de acordo com a proximidade da fonte de calor.

$\mathrm{O}$ processo de secagem com temperatura do ar, no final da câmara, de $27^{\circ} \mathrm{C}$, alcançando $62^{\circ} \mathrm{C}$ durante o processo e finalizando $\operatorname{com} 50^{\circ} \mathrm{C}$, devido à redução progressiva da umidade do ar secante após sua passagem pela massa de sementes, torna-o mais seco. Analisando-se o comportamento das temperaturas de secagem durante o processo, nota-se que a temperatura do ar de secagem foi estável por causa da utilização de gás como combustível. Observa-se também, que não ocorre o transporte de partículas ou materiais incombustíveis para o ar, como na secagem tradicional ao empregar lenha. Verificou-se que, na última fase (T4), há redução na temperatura da massa em função de ter sido feito aeração para resfriamento da massa de sementes.

Constata-se redução significativa no teor de água das sementes de trigo (Figura 1) durante o processo de secagem estacionária empregando-se gás GLP. Nota-se aumento no teor de água das sementes nos pontos de verificação 2 e 3, durante os primeiros 45 minutos de secagem, proporcionando um coeficiente de determinação menor que as demais curvas. Tais resultados sugerem que em função da migração da corrente de ar úmido, originária da passagem do ar quente pela massa de semente, localizada próxima à fonte de calor (P1), ocorra elevação do teor de água das sementes em posição P2 e P3.

Nas camadas mais distantes da entrada do ar, pode ocorrer aumento do teor de água das sementes, em conseqüência da condensação provocada pela passagem do ar úmido por camadas com temperaturas mais baixas (Brooker et al., 1974). Neste trabalho, tal situação é observada, sendo a velocidade da secagem inversamente proporcional à umidade relativa do ar (Tabela 1$)$.

Verificou-se que, o ponto 3, por estar mais distante da fonte de calor, apresenta maior teor de água final $(13,9 \%)$ e menor velocidade de secagem $\left(0,73 \mathrm{pph}^{-1}\right)$ em relação aos pontos mais próximos da fonte de calor (teor de água final de 12,4\%, para P1 e 12,6\%, para P2, ambos com velocidade de secagem de $1,00 \mathrm{pph}^{-1}$ ), conforme Tabela 1 e Figura 1. Secando trigo em secador estacionário empregando lenha, Beusso et al. (2001) também observaram velocidades de secagens distintas para P1, P2 e P3, obtiveram 0,72pph ${ }^{-1}$ para P3 e $1,00 \mathrm{pph}^{-1}$ para P1. Por outro lado, Cavariani et al. (1999) observaram diferença na velocidade de secagem, a partir dos pontos intermediários aos mais externos.

Constata-se, na Figuras 1, que há redução nos teores de água, com diferença na velocidade de secagem em cada um dos pontos verificados. A velocidade média de secagem obtida no secador empregando gás foi de $0,91 \mathrm{pph}^{-1}$, entre $15,3 \%$ e $13,0 \%$, empregando a temperatura máxima de $62^{\circ} \mathrm{C}$ no ar de secagem. Rosa (1966) também em sementes de trigo obteve $1,7 \mathrm{pph}^{-1}$ a temperatura de $40^{\circ} \mathrm{C}$ e $3,0 \mathrm{pph}^{-1}$ a $50^{\circ} \mathrm{C}$. Entretanto, Silva Filho (1997), na secagem intermitente de sementes de

TABELA 1. Acompanhamento das temperaturas do ar e da massa e do teor de água de sementes de trigo, durante a secagem empregando gás liquefeito de petróleo, nos três pontos de observação (P1, P2, P3). Castro - PR 2000.

\begin{tabular}{ccrrrrrr}
\hline \multirow{2}{*}{ Tempo Minutos } & \multirow{2}{*}{$\mathrm{T}^{\circ} \mathrm{C}$ ar } & \multicolumn{2}{c}{$\mathrm{T}^{\circ} \mathrm{C}$ massa nos Pontos } & \multicolumn{2}{c}{ Teor de água \% nos Pontos } \\
\cline { 3 - 7 } & 27,0 & $\mathrm{P} 1$ & $\mathrm{P} 2$ & $\mathrm{P} 3$ & $\mathrm{P} 1$ & $\mathrm{P} 2$ & $\mathrm{P} 3$ \\
\hline 0 & $50 / 62$ & 4,0 & 27,0 & 27,0 & 15,3 & 15,3 & 15,3 \\
45 & $50 / 62$ & 49,7 & 32,7 & 29,3 & 13,9 & 16,0 & 16,9 \\
90 & $50 / 50$ & 46,3 & 42,7 & 36,0 & 12,7 & 13,5 & 15,2 \\
135 & $31 / 31$ & 31,0 & 31,0 & 43,3 & 12,3 & 12,3 & 13,1 \\
180 & & & & 1,0 & 12,4 & 12,6 & 13,9 \\
\hline Velocidade de & & & & 1,00 & \multirow{2}{*}{1,00} & 0,73 \\
Secagem $\left(\mathrm{pph}^{-1}\right)$ & & & & & &
\end{tabular}




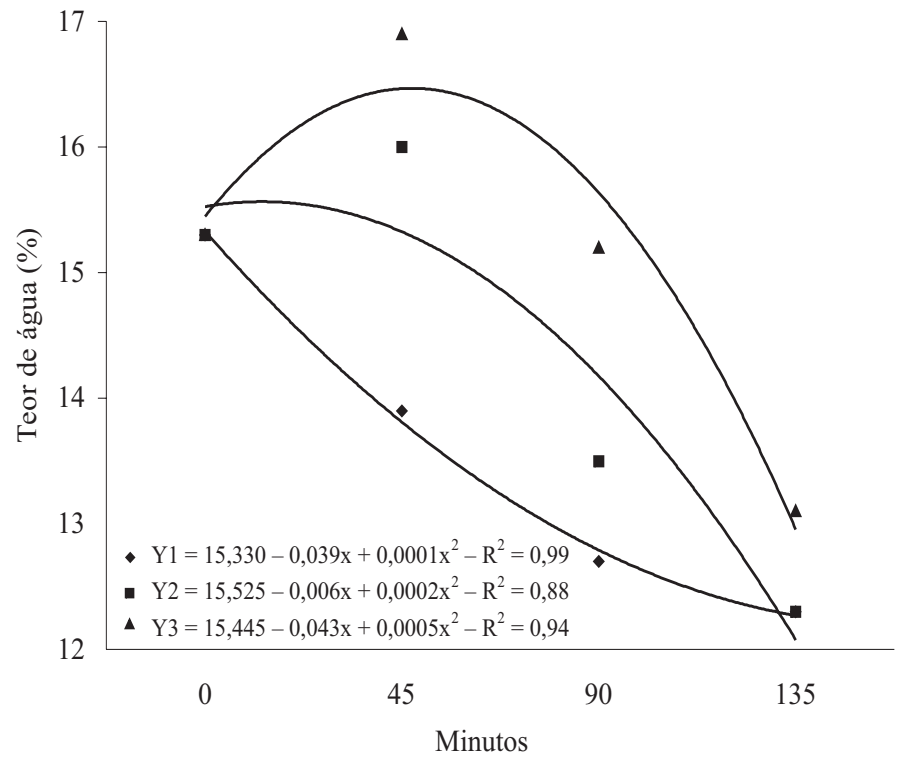

FIGURA 1. Curvas representativas do teor de água de sementes de trigo OR-I, nos três pontos de observação, submetidas à secagem estacionária utilizando GLP, em função do tempo de secagem. Castro - PR, 2000.

trigo, encontrou 1,1 $\mathrm{pph}^{-1}$.

Na secagem de sementes de milho, em secador estacionário, Cavarini et al. (1999) obtiveram uma velocidade de secagem de $0,39 \mathrm{pph}^{-1}$ à temperatura de $48^{\circ} \mathrm{C}$ e fluxo do ar de $24,7 \mathrm{~m}^{3} \cdot \mathrm{min}^{-1} \cdot \mathrm{t}^{-1}$. Observaram que a velocidade de secagem depende do avanço da frente de secagem, sendo reduzida à medida que aumenta a distância das sementes ao cilindro central, resultado este, também constatado no presente trabalho, embora realizado em secador diferente, mas com princípios semelhantes (Figura 1 e Tabela 1).

Em trabalho realizado com secagem de sementes de arroz, em silo secador com distribuição radial de ar, Corrêa (1981) verificou que as amostras do terço médio, com teor de água inicial de $18 \%$, secaram a velocidade média de secagem de 0,30 $\mathrm{pph}^{-1}$, bem inferior ao presente trabalho.

Constatou-se diferença significativa na germinação entre os três pontos (P1, P2, P3) da massa de semente em relação à fonte de calor, avaliados logo após a secagem. Aos 180 minutos de secagem a maior germinação encontrada foi em P1 e a menor em P2 quando secas com temperatura máxima do ar de secagem de $62^{\circ} \mathrm{C}$ durante três horas de secagem (Tabela 2). As variações observadas, possivelmente sejam oriundas de fatores não controlados durante a realização dos testes, uma vez que as amostras de sementes passaram apenas pela pré-limpeza, onde geralmente não são descartadas as sementes danificadas. Por outro lado, Pasin (1991) não encontrou diferenças significativas na germinação entre os pontos na secagem estacionária de soja, utilizando temperatura do ar de secagem máxima de $41^{\circ} \mathrm{C}$ e mínima de $26^{\circ} \mathrm{C}$.

Ainda na Tabela 2, destaca-se que as médias de germinação das sementes de trigo de todos os tratamentos, na primeira época, apresentam-se superiores para P1 em relação a P2 e P3, evidenciando possível efeito na qualidade fisiológica das sementes em função da sua localização no secador. Mas, a inexistência de efeitos fisiológicos nas sementes, provenientes do posicionamento da massa, foi anteriormente observada em secagem estacionária com fluxo radial por Corrêa (1981), ao avaliar sementes de arroz com temperatura máxima de secagem de $32,5^{\circ} \mathrm{C}$ e mínima de $28^{\circ} \mathrm{C}$.

Com os valores obtidos de emergência em campo e

TABELA2. Porcentagem de germinação de sementes de trigo, nos três pontos de amostragem, em função do tempo de secagem logo após a secagem. Castro-PR, 2000.

\begin{tabular}{cccc}
\hline Tempo (min) & P1 & P2 & P3 \\
\hline 0 & $90 \mathrm{a}$ & $89 \mathrm{a}$ & $90 \mathrm{a}$ \\
45 & $90 \mathrm{a}$ & $91 \mathrm{a}$ & $90 \mathrm{a}$ \\
90 & $92 \mathrm{a}$ & $90 \mathrm{a}$ & $90 \mathrm{a}$ \\
135 & $92 \mathrm{a}$ & $90 \mathrm{a}$ & $91 \mathrm{a}$ \\
180 & $93 \mathrm{a}$ & $87 \mathrm{~b}$ & $90 \mathrm{a}$ \\
\hline Média & 92 & 90 & 90
\end{tabular}

Médias seguidas da mesma letra minúscula, nas colunas e maiúscula, para as linhas não diferem entre si pelo teste de Tukey a 5\% de probabilidade.

envelhecimento acelerado, na primeira época e após seis meses de análise, não foram observadas diferenças significativas, entre os três pontos de observação (P1, P2, P3) e tempo de secagem (0-180min).

Ao analisar o comportamento fisiológico de sementes de milho, utilizando a temperatura do ar de secagem máxima de $48^{\circ} \mathrm{C}$ e mínima de $40^{\circ} \mathrm{C}$, Cavarini et al. (1998), também não observaram alterações na qualidade fisiológica nos diferentes pontos do secador. Além disso, Rosa (1966) observou que temperaturas do ar acima de $60^{\circ} \mathrm{C}$ comprometem a germinação de sementes de trigo. De acordo com os resultados obtidos por Nweist e Bnice citado por Silva Filho (1997), temperatura do ar de $66^{\circ} \mathrm{C}$ não afeta a germinação de sementes de trigo. 


\section{CONCLUSÕES}

A velocidade de secagem reduz à medida que aumenta a distância das sementes ao cilindro central. A temperatura na massa de sementes aumenta gradativamente nos pontos mais próximos à fonte de calor durante a secagem.

Os resultados do teste de germinação e vigor mostram a possibilidade de utilização do gás liquefeito de petróleo como combustível na secagem estacionária de sementes de trigo.

A temperatura do ar de secagem permanece estável durante o processo, com a utilização do gás liquefeito de petróleo.

\section{REFERÊNCIAS}

AHRENS, D.C.; VILLELA, F.A.; DONI FILHO, L. Qualidade fisiológica e industrial de sementes de aveia-branca (Avena sativa) na secagem intermitente. Revista Brasileira de Sementes, Brasília. v. 22, n.2, p. 12-20, 2000a.

AHRENS, D.C.; VILLELA, F.A.; DONI FILHO, L. Secagem estacionária de aveia-branca (Avena sativa) empregando diferentes temperaturas do ar. Revista Brasileira de Sementes, Brasília, v. 22, n.2, p. 6-11, 2000b.

AHRENS, D.C.; LOLLATO, M.A. Eficiência de secadores estacionários de fluxo radial e intermitente rápido: efeitos sobre a qualidade de sementes de feijão. Revista Brasileira de Sementes, Brasília, v.19, n.1, p.28-33, 1997.

BEUSSO, D.R; BERTI, M.; AHRENS, D.C. Qualidade física de sementes de trigo (Triticum aestivum) na secagem estacionária empregando a lenha. In: CONGRESSO BRASILEIRO DE SEMENTES, 13, 2001. Curitiba. Anais... Londrina: Informativo ABRATES, p. 78, 2001

BRASIL, Ministério da Agricultura e Reforma Agrária. Regras para análise de sementes. Brasília: SNDA/DNDV/CLAV, 1992. 365 p.
BROOKER, D.B.; BAKKER-AEKEMA, F.W.; HALL, C.W. Drying and storage of grains and oilseeds. Westport: AVI, 1992. 450p.

CARVALHO, N.M.A secagem de sementes. Jaboticabal: FUNEP, 1994. 165p.

CAVARINI, C.; SILVA, W.R.; MIRANDA, L.C.; NAKAGAWA, J.; BELGIORNO, D.C. Secagem estacionária de sementes de milho com distribuição radial do fluxo de ar. I-Qualidade fisiológica de sementes. Revista Brasileira de sementes, v. 20, n.2, p.433-440, 1998.

CAVARINI, C.; SILVA, W.R.; MIRANDA, L.C.; NAKAGAWA, J.; BELGIORNO, D.C. Secagem estacionária de sementes de milho com distribuição radial do fluxo de ar. II-Andamento físico. Revista Brasileira de Sementes, v. 21, n.1, p.7-17, 1999.

CORREAA, C.F. Secagem de sementes de arroz (Oryza sativa L.) em silo secador com distribuição radial de ar. 1981. 85f. Dissertação (Mestrado em Ciência e Tecnologia de Sementes) Faculdade de Agronomia "Eliseu Macial”, Universidade Federal de Pelotas, Pelotas, 1981.

NAVRATIL, R.J.; BURRIS, J.S. The effect of drying temperature on corn seed quality. Canadian Journal of Plant Science. Otawa v.4, p.478-496, 1984.

PASIN, N.H. Secagem estática de sementes de soja. Informativo ABRATES, Londrina. v.2, n.1, p.33-39. 1991.

ROSA, O.S. Temperaturas recomendadas para a secagem de sementes de trigo e arroz utilizando o método intermitente. In: SEMINÁRIO PANAMERICANO DE SEMILLAS, 5., 1966, Maracay. Anais... Maracay: 1966. 27 p.

SILVA FILHO, P.M. Processo de secagem, desempenho da semente e qualidade industrial do trigo. 1997. 64f. Tese (Doutorado em Ciência e Tecnologia de Sementes) Faculdade de Agronomia “Eliseu Maciel” da Universidade Federal de Pelotas, Pelotas. 1997.

VILLELA, F.A.; SILVA, W.R. Curvas de secagem de milho utilizando o método intermitente. Scientia Agrícola, Piracicaba. v.49, n.1, p.145-153, 1992.

ULTRAGAZ. Disponível em <http://www.ultragaz.com.br/ secagem.htm> Acesso em: 10 out. 2000. 